\title{
Forces of nature
}

\section{Sophie Cook UK research editor, Navjoyt Ladher head of scholarly comment}

The BMJ

We have another bumper crop of Christmas articles in The BMJ this year, so read on as you raise a glass to the festive season—but not too big a glass (doi:10.1136/bmj.j5623).

The natural world features in several papers, exploring links between environmental conditions and health: from weather and joint pain (doi:10.1136/bmj.j5326) to thunderstorm asthma (doi:10.1136/bmj.j5636) and the effect of a full moon on deaths of motorcyclists (doi:10.1136/bmj.j5367).

The built environment is key too. Evidence is growing for the health benefits of green spaces, and Juliet Dobson explores how hospital gardens, common before the second world war, are making a comeback (doi:10.1136/bmj.j5627).

Benjamin Mazer describes how our built surroundings can help us make sense of the medical landscape, as he draws an analogy between brutalist architecture and the drive to utility often underlying modern healthcare (doi:10.1136/bmj.j5676).
On to toddler favourite Peppa Pig. Catherine Bell asks whether the paternalism and questionable prescribing practices of the television series' resident GP, Dr Brown Bear, could be promoting overuse of healthcare (doi:10.1136/bmj.j5397). We wonder how Dr Brown Bear might approach the much debated phenomenon of "man flu," which Kyle Sue concludes may have some basis in fact (doi:10.1136/bmj.j5560).

Though we can't always change the factors in our environment that affect our health, acknowledging their role is important-as is helping people affected by adverse conditions, whether environmental or not. Our Christmas appeal this year is raising money for Médecins Sans Frontières, whose staff and volunteers bring medical aid to some of the people around the world who need it most, such as those trapped by the crossfire in Yemen (doi:10.1136/bmj.j5722). Please support them with your usual generosity (www.msf.org.uk/bmj). 